RGSA - Revista de Gestão Social e Ambiental

Set.- Dez. 2009, V.3, No.3, p. 85-101

www.gestaosocioambiental.net

\title{
DESAFIOS E PRÁTICAS PARA A INSERÇÃO DA TECNOLOGIA DA INFORMAÇÃO VERDE NAS EMPRESAS BAIANAS: UM ESTUDO SOB A PERSPECTIVA DOS PROFISSIONAIS DE TECNOLOGIA DA INFORMAÇÃO
}

\author{
Marcos Ramos de Almeida Paraíso ${ }^{1}$ \\ Thereza Olívia Rodrigues Soares ${ }^{2}$ \\ Leandro Antonio de Almeida ${ }^{3}$
}

\section{RESUMO}

O objetivo do estudo é analisar as dificuldades e as práticas existentes para a adoção da Tecnologia da Informação Verde (TI Verde) nas empresas. Traz inicialmente um breve histórico do conceito de TI Verde, a partir do pressuposto que as posturas empresariais ecologicamente corretas referentes à tecnologia da informação entram em conflito com as necessidades das empresas em expandir os seus parques tecnológicos para garantir a competitividade que tem as suas bases na inovação. Busca-se contribuir com os estudos acerca dos maiores problemas ambientais no mundo atual: o alto consumo de matérias-primas não renováveis, lixo tecnológico descartado inadequadamente e liberação de poluentes que contaminam o solo e os rios. A metodologia utilizada foi quantitativa e qualitativa: foram aplicados 24 (vinte e quatro) questionários para gerentes e técnicos da área de TI de empresas de diversos ramos de atuação na cidade de Salvador-Bahia. Apesar da maioria dos entrevistados possuírem conceito formado sobre a TI Verde, percebe-se que a maioria das organizações não a priorizam na sua pauta de estratégias e práticas de responsabilidade sócioambiental.

Palavras-chave: Tecnologia da Informação Verde, Responsabilidade Sócio-ambiental Corporativa, Salvador - Bahia.

\section{ABSTRACT}

The main goal of this paper is to analyze practices and troubles to adopt Green Information Technology (Green IT) in companies. First, it brings a short history of the Green IT concept, presuming that IT ecological actions come into conflict with corporate needs of spreading their technological devices to assure competitiveness, based on innovation. The present article

\footnotetext{
${ }^{1}$ Bacharel em Administração pela Faculdade 2 de Julho. E-mail: adm.marcosparaiso@gmail.com

${ }^{2}$ Mestre em Desenvolvimento Humano e Responsabilidade Social, Especialista em Gerenciamento Ambiental e Bacharel em Processamento de Dados (UFBA). Professora de Gestão da Tecnologia da Informação do Curso de Administração da Faculdade 2 de Julho. E-mail: therezaolivia@yahoo.com.br

3 Doutorando em História pela Universidade de São Paulo - USP. Professor de Ensino de História da Universidade Federal do Recôncavo da Bahia-UFRB. E-mail: leandroaalmeida@hotmail.com
} 
aims to cooperate with the studies about one of the most important environmental troubles nowadays: the over-consumption of not renewable inputs, improper destination of e-waste and pollution emission contaminating soil and rivers. The methodology used was quantitative and qualitative: 24 (twenty-four) questionnaires for IT managers and technicians working at companies of several segments in Salvador, Bahia, Brazil were applied. Despite most interviewees have a pre-established concept of Green IT, the organizations don't prioritize it in their strategies and practices of social and environmental responsibility.

Keywords: Green Information Technology, corporate social and environmental responsibility, Salvador-Bahia.

\section{INTRODUÇÃO}

A evolução tecnológica nos dias de hoje é muito rápida, o que faz com que os equipamentos fiquem obsoletos em pouco tempo, causando um grande problema: o que fazer com os computadores antigos? Muitos computadores têm o destino dos aterros sanitários, despejando várias substâncias altamente tóxicas, no solo, nos lençóis freáticos, prejudicando tanto a saúde humana, quanto a vida dos outros seres vivos. Ou então, são incinerados, liberando da mesma forma centenas de substâncias na atmosfera. Na tentativa de melhorar os problemas do aquecimento mundial e os outros impactos ambientais, surge o conceito de Tecnologia da Informação Verde (TI Verde), que tem os objetivos de economizar recursos e/ou reduzir gastos de energia, utilizando de normas e padrões. Cada vez mais as organizações precisam de computadores que levam menos tempo para processar dados. E quando a organização muda o sistema, trazendo outro sistema melhor, tendo que mudar todas as máquinas, o que é feito? Talvez o maior problema no mundo, que vem causando grande preocupação, é o aquecimento global, e os estudos sobre a Tecnologia da Informação (TI) não tinham se preocupado com este problema até certo tempo, o que acaba tornando a TI um agente deste aquecimento global.

A fabricação é outro problema, por exemplo, para fabricar um monitor CRT 17 polegadas, demandaram em 2004, 240 quilos de combustíveis fósseis, 22 quilos de produtos químicos e cerca de 1,4 mil litros de água. Organizações que fabricam servidores, computadores, entre outros, têm se preocupado em produzir equipamentos verdes como, por exemplo, os monitores LCD que são menos agressivos ao meio ambiente do que os monitores convencionais. Outro debate que está ganhando espaço na agenda dos CIO's - Chief Information Officer - é a energia que é gasta nos Data Centers.

Assim sendo, coloca-se aqui a seguinte questão: quais os desafios e as práticas existentes para a inserção da TI Verde nas empresas baianas? O pressuposto é que as metas organizacionais de atualização tecnológica, uso intensivo da tecnologia para a competitividade e evolução dos parques tecnológicos entram em conflito com a adoção de práticas ambientalmente corretas. Esses computadores, celulares e outros dispositivos eletroeletrônicos que são jogados nos aterros sanitários, são denominados de Lixo Eletrônico ou Lixo Tecnológico. A Agência Européia, segundo Macohin (2008) prevê nos próximos anos que este lixo crescerá cerca de três vezes mais, podendo chegar à incrível marca de quarenta milhões de toneladas por ano. Quanto mais se produz, maior será a quantidade de resíduos e/ou lixo tecnológicos gerados tanto na produção como no descarte pelos usuários, neste aspecto é necessária a Gestão Ambiental nas organizações e o termo Sustentabilidade, onde os CIO's, gestores e técnicos de TI devem se preocupar com a quantidade de materiais demandados para a produção, a quantidade de materiais desperdiçados e com o destino dos produtos quando não tiverem mais utilidade e que serão descartados no meio ambiente. 
Para analisar o pressuposto colocado, esta pesquisa teve como objetivo geral analisar as dificuldades e as práticas existentes para a adoção da TI Verde em empresas baianas diante da evolução tecnológica. Os estudos e pesquisas acerca dessa temática ainda são muito incipientes, conforme foi observado na pesquisa bibliográfica empreendida, e, dessa forma, este trabalho pretende contribuir para novas pesquisas em torno deste problema, diante das conseqüências como o alto consumo de matérias-primas não renováveis, grandes acúmulos de lixo tecnológico, liberação de gazes poluentes e substâncias que contaminam o solo, rios, causando assim o aquecimento global.

\subsection{PROCEDIMENTOS METODOLÓGICOS}

A pesquisa utilizou abordagens metodológicas quantitativas e qualitativas, com a realização de uma pesquisa exploratória. Segundo Roesch (2007), a abordagem qualitativa tem o objetivo de aprofundar o nível de conhecimento de algum conceito, o que foi buscado neste trabalho através das questões abertas do questionário. Já a abordagem quantitativa tem o objetivo de explorar um tema de forma mais ampla e geral, fornecendo um conhecimento panorâmico do objeto de estudo. É indicada para abordar percepções de um tema que foi pouco estudado, como no caso da TI Verde, que ainda possui poucos trabalhos ou artigos acadêmicos publicados. A utilização mesclada de tais abordagens embasou a realização de uma pesquisa exploratória.

Foram utilizados livros, artigos, teses e a internet como fonte de pesquisa. Como se trata de um tema muito novo, Tecnologia da Informação Verde, e ter poucos trabalhos e pesquisa na literatura, a Internet tornou-se uma fonte que mais se debate sobre o assunto, porém, o que foi utilizado por esta via, foi pesquisado de fontes rigorosamente seguras. Os livros e artigos contribuíram com embasamento sobre o conceito da Tecnologia da Informação, que logo depois deu suporte à construção para o conceito da Tecnologia da Informação Verde.

Foram aplicados 24 (vinte e quatro) questionários aos profissionais de 24 (vinte e quatro) organizações das mais diversas áreas, como: empresa de comunicação, empresa farmacêutica, empresa de aviação aérea, empresa de telefonia móvel, callcenters, instituições de ensino superior, empresas desenvolvedoras de softwares e de soluções de TI, organizações não governamentais, organizações públicas de TI, órgãos públicos não direcionados à TI, que porém possuem o setor de Tecnologia da Informação. Os questionários, contendo questões fechadas e abertas, foram distribuídos por email através de uma lista de contatos e relacionamentos de profissionais que atuam na área de TI.

\section{TECNOLOGIA DA INFORMAÇÃO VERDE}

Nos dias atuais, as questões ambientais se fazem presentes nas mais diversas áreas, e com a área da Tecnologia da Informação não poderia ser diferente. A evolução da TI nas organizações trouxe inúmeros benefícios, principalmente a maximização da eficiência produtiva. Diminuindo os custos de produção, os produtos ficaram mais accessíveis ao consumidor, que, por sua vez, criaram uma característica do alto consumismo, o que ocasiona grandes impactos ambientais, seja pelos resíduos de produção e/ou no descarte de produto.

A TI se torna um agente passivo do aquecimento global, pois com os avanços tecnológicos as organizações chegaram a nível altíssimo de produção e com esse aumento da produção acarretou a escassez de matérias-primas não renováveis. Por fim, o conceito de TI Verde também evolui, contudo ainda não existe na literatura um conceito pronto. De acordo com Soares (2005), a definição de Tecnologia Verde: 
Trata-se de um conceito que prega o uso de tecnologias politicamente corretas, que sejam ecológicas e consumam menos energia para diminuir a quantidade de $\mathrm{CO} 2$ (dióxido de carbono) que elas jogam no ar. A prática também incentiva a reciclagem e reutilização dos equipamentos de informática. (Soares, 2005, para. 1, grifo do autor).

Então, entende-se como Tecnologia da Informação Verde o conjunto de hardware e software tanto no contexto do uso organizacional como no uso pessoal, que trabalham de forma politicamente e ambientalmente corretos, visando a economia de matérias-primas e energia, reduzindo da mesma forma resíduos produzidos na operação, diminuindo e/ou eliminando a quantidade de dejetos jogados no meio ambiente, assim causando menos impactos ao meio ambiente.

A Tecnologia da Informação Verde surgiu como uma possível resposta aos grandes problemas do aquecimento global e/ou impacto ambiental. Seus maiores enfoques são de reduzir a quantidade de matérias-primas não renováveis demandada para a produção, evitando o desperdício dos insumos na produção, redução do consumo de energia elétrica, e minimização da utilização de substâncias altamente tóxicas ao meio ambiente, trocando por substâncias menos agressivas.

Como afirma Pendler (2009), a TI Verde tem um grande valor econômico no mundo, pois esses números de desperdícios podem ser transformados em economia, englobando a quantidade de insumos para fabricação de produtos, conforme a pesquisa do professor Ruediger Kuer Secretário-Executivo da Solving the E-waste Problem (STEP), que mostra que durante uma fabricação de um computador são demandados cerca de mil e oitocentos quilos de vários insumos, sendo que mil e quinhentos somente de água.

A Tecnologia da Informação Verde é considerada uma importante força para atenuar o avanço do aquecimento global, porém o grande problema de transformar uma organização em verde seria o custo envolvido nessa mudança, a troca de um novo maquinário. A emissão de gás carbônico na atmosfera é outro fator que pesa no aquecimento global, e, preocupados com isso, alguns países desenvolvidos criaram alguns acordos de redução de emissão de $\mathrm{CO}_{2}$, assim onerando as organizações que não atingirem as metas de emissão do gás. Desta forma, forçam também as mesmas organizações a reduzirem o consumo de energia elétrica, pois quanto mais computadores ligados, maior será a emissão de gases nocivos.

Segundo Zmogimski (2009a), o problema do carbono lançado na atmosfera pode ser solucionado, pois o autor comenta sobre a descoberta por Aldo Steinfeld no Instituto de Tecnologia da Suíça, que reside na idéia de aquecer uma quantidade de ar poluído em um cilindro com hidróxido de sódio, quando este cilindro é aquecido a temperaturas acima de $400^{\circ} \mathrm{C}$, o carbono reage com o hidróxido, assim o oxigênio fica livre do carbono que por sua vez se transforma em carbonato de cálcio que não é tóxico e pode ser enterrado. Porém, o mesmo autor informa que esta tecnologia é muito cara e consume muita energia elétrica para aquecer o ar a $400^{\circ} \mathrm{C}$, no entanto, o inventor propõe o uso de energia solar, com isso, o processo de transformação seria feito no deserto, onde o sol é muito forte.

A quantidade de energia demandada para as fábricas continuarem a produzir cem por cento e para os centros urbanos, vem aumentando cada vez mais, se tornando um dos maiores problemas discutidos no mundo. Fala-se muito na utilização de energias renováveis, como a energia eólica, energia solar e ate a utilização do movimento das ondas para geração de energia, porém como dito antes, as tecnologias limpas ainda custam muitos caros para as organizações, que enfocam nos custo financeiros. Segundo Pendler (2009, para. 3), "nos EUA, o Departamento de Energia publicou que em mais de 100 milhões de computadores usados nas organizações, mais de $60 \%$ ficam 24 horas, o que pode significar cerca de 70.000 
dólares ano desperdiçado em energia elétrica", pois os computadores ficam ligados durante a noite para fazerem atualizações de programas ou ficam ligados para os programas de antivírus verificar as máquinas. Conforme pesquisa publicada na Redação Info (2009), realizada pelo Departamento de Energia dos Estados Unidos em parceria com a Universidade de Stanford, nos últimos sete anos, os custos com energia aumentaram em torno de $40 \%$. E este fator anda paralelamente junto ao problema do aquecimento global. Sendo que $20 \%$ destes gastos são direcionados para o funcionamento dos Data Centers.

Uma novidade apresentada em 27 de Abril de 2009, segundo Moreno (2009) reside em um monitor que possui um sensor capaz de desligar o monitor temporariamente quando o usuário sai para ir ao banheiro ou beber água, por exemplo. O sensor, segundo a empresa fabricante, também é capaz de diferenciar os usuários das cadeiras. E possui também um dispositivo que estimula os usuários a fazerem uma pausa, para descansos dos olhos. Com isso percebe-se que a economia de energia torna-se ponto crucial para a inovação de tecnologias mais limpas. Conforme a Zmogimski (2009b), uma organização já vende um tipo de hélice que pode fornecer energia suficiente para aquecer a casa no inverno, esquentar água. O equipamento custa US\$ 10 mil, mas se a idéia se massificar o custo pode cair. Então, qualquer casa com o equipamento pode ser auto geradora de sua energia elétrica demandada.

Os Data Centers também estão ganhando espaço nas discussões ambientais, tanto na questão de economia de energia como também na redução de emissão de $\mathrm{CO}_{2}$. Novas tecnologias permitem que os novos Data Centers tenham mais capacidade de armazenamento, com isso reduzindo a quantidade de CPD dentro das organizações. Data Centers que acabam esquentando menos, necessitando cada vez menos de refrigeração, economizando energia.

A vida útil de um computador hoje é de 18 meses, pois acredita-se que a cada 18 meses a tecnologia evolui, seja no tocante dos hardwares e/ou softwares, e os computadores ficam obsoletos. Este fator também ajuda no alto consumo dos PC's, como também no acumulo do lixo tecnológico, pois os usuários preferem comprar um novo computador, a atualizá-lo comprando novas peças. Há usuários que trocam seus computadores em bom estado e funcionando, por um novo, por causa de estética, status, um melhor desempenho, porém o que eles não têm consciência é que para se fabricar um computador é demandado quase duas toneladas de matérias-prima e quase todas elas não renováveis. Entretanto, andando na contramão é o custo de ter uma atitude mais verde, que é a atualização. É mais caro fazer o upgrade ou atualização comprando novas peças individuais para o computador.

A Executive Briefing traz uma discussão bastante relevante na relação do lixo tecnológico e a reciclagem. Para a Executive Briefing a reciclagem traz inúmeras desvantagens para o meio ambiente, deste modo contrapondo a visão de vários grupos ambientalistas como o Friends of the Earth e Greenpeace que defendem a reciclagem dos produtos eletroeletrônicos. A revista ainda explica que as reciclagens de produtos eletrônicos são bem diferentes da reciclagem de latinhas de alumínio, por exemplo. E ainda apresenta cinco razões que mostram porque a reciclagem é ruim para o meio ambiente, são elas: a reciclagem polui, pois segundo autor é necessário um trabalho monstruoso, aquecer vários componentes para separar os metais como ouro e prata dos outros dispositivos, o que gera gases altamente poluentes na atmosfera; a reciclagem não reduz a produção de dispositivos eletrônicos, pois quando se recicla é necessário produzir mais dispositivos para suprir a demanda existem pelas peças obsoletas; reciclar pode também não funcionar, pois reciclando o produto fica mais caro, com isso, nem todo consumidor possui o poder aquisitivo ou acham adequado comprar uma peça nova mais barata; a reciclagem não melhora os produtos; a reciclagem alimenta um dos maiores problemas ambientais: o armazenamento, pois muitos usuários pretendem fazer a entrega dos seus computadores e celulares para a empresa que faz 
reciclagem, porém por motivo maior, os usuários estão ocupados no momento e deixam para depois e passam até anos com os aparelhos bons guardados dentro de casas e depósitos ao invés de dar ou vender para pessoas que poderiam utilizá-los antes de ficarem obsoletos.

Com isso, para confirmar seu pensamento o autor colocar seis razões para a solução deste problema. A princípio, o autor defende fazer o re-upgrade, que seria a reutilização dos dispositivos antigos. Com isso, reaproveitando o material rejeitado pelos primeiros usuários, não será necessário as fabricas produzirem da mesma forma, assim podendo diminuir a quantidade de dispositivos no meio ambiente. Outro motivo é que o usuário vendendo seu equipamento, ele acaba angariando novos recursos para a compra de um novo computador. Com isso, o problema do armazenamento de equipamentos obsoletos, seja por falta de uso, ou porque está com defeito acaba, pois o usuário, como visto antes, vende seu equipamento para uma empresa ou para outro usuário e não armazena.

\section{LIXO TECNOLÓGICO}

A evolução tecnológica possibilitou o avanço também da produção, criando a produção em massa. Com isso, os custos de produção dos componentes dos computadores caíram, beneficiando a quase todas as classes sociais, ampliando nos últimos anos a taxa de computadores nos lares. Com esse avanço o preço do computador caiu, gerando ou até mesmo tornando mais visível uma característica do capitalismo, o alto consumo. Assim, acredita-se que a vida média de um computador que na década de 90 era de 6 anos, hoje é de 18 meses, pois a tecnologia, softwares evoluem, sendo que a máquinas mais antigas não suportam este avanço, levando os usuários a comprarem novas máquinas, visto que a atualização fica mais caro. Desta forma, os consumidores compram novos PC's e deixam guardados ou jogam fora, normalmente nos lixos domésticos, os computadores antigos.

O acúmulo desses computadores ou qualquer tipo de aparelho eletro-eletrônico cria o Lixo Eletrônico. Esse tipo de lixo é o que mais cresce no mundo, segundo a Agência Européia do Meio Ambiente o lixo eletrônico ou tecnológico cresce três vezes mais que qualquer outro tipo de lixo. Um computador possui mais de 1.000 componentes, sendo muitos deles altamente perigosos ao meio ambiente, são eles: chumbo, cádmio, mercúrio, cromo hexavalente, plásticos, substâncias retardantes de fogo. Segundo SPCTi Reciclagem (2009), durante o período de 1997 a 2004 cerca de 315 milhões de computadores ficaram obsoletos nos Estados Unidos da América (EUA), e estes conteriam cerca de 600 mil toneladas de chumbo, 600 mil toneladas de cromo e 200 mil toneladas de mercúrio. Números que assustam as organizações não governamentais (ONGs) que se preocupam com o aquecimento global. $\mathrm{O}$ chumbo quando lançado nos lençóis freáticos contaminam os rios e da mesma forma os peixes, estes sendo ingeridos em grande quantidade por gestantes pode ocasionar má formação do feto, câncer e conseqüentemente a morte.

Este é um grande desafio para as organizações do meio tecnológico, o que fazer com os produtos antigos? Os EUA mandam seu lixo tecnológico para os países subdesenvolvidos, pois a mão-de-obra é mais barata e nem se preocupam se este lixo vai ter tratamento adequado, pois na Ásia, um dos continentes que mais recebe lixo, não existe praticamente leis ambientais. Além disso, os EUA não participam da Convenção da Basiléia, que tem como objetivo a proibição da exportação de lixo tóxico de países ricos para os países em desenvolvimento, mesmo com o intuito de reciclagem. Existem projetos de lei para que os usuários fiquem mais tempo com seus computadores, forçando a fazerem o upgrade que é a atualização das peças velhas por novas, com a instalação de pontos especiais de coleta, para que este tipo de lixo não vá parar nos aterros sanitários e contaminar o meio ambiente. 
As organizações poderiam fazer, como outra forma de diminuir o impacto ambiental, seria a logística reversa dos produtos fabricados por elas ou por outras organizações, na tentativa da reciclagem do máximo possível de produtos obsoletos. Entende-se por Logística Reversa todo o movimento feito para que o produto depois de usado volte para o mesmo local do início do ciclo produtivo, para que seja tomada a decisão se o produto será reciclado dando origem a matérias-primas secundárias ou se será reutilizado seus componentes.

Assim, o problema do lixo eletrônico seria um problema a menos no mundo, porém ainda são poucas organizações que tem um projeto na área da logística reversa, pois os custos são altos para fazer a reciclagem dos produtos, o que encareceriam os novos produtos. Conforme a Computerworld (2009) um estudo feito pela a IBM mostra que, mais de $70 \%$ das médias companhias brasileiras realizam ou pretendem realizar projetos voltados para as questões ambientais. Segundo o mesmo estudo, o Brasil é o país que mais conta com servidores virtuais, presente em $65 \%$ das empresas. Outra iniciativa voltada para os problemas ambientais vem por parte da Universidade de São Paulo (USP). Em dezembro de 2008, segundo Dias (2008), a USP lançou um processo licitatório, onde a mesma demandava computadores livres de metais pesados como o chumbo, cádmio, níquel, cobalto, entre outros. Porém, existia um grande problema.

No Brasil existem poucas empresas que trabalham com produtos livres de metais perigosos, com isso, a USP decidiu fazer um processo de licitação com as especificações dos computadores desejáveis ao invés do obrigatório. Participaram desse processo quatro empresas, sendo que a Itautec foi a que empresa que venceu a licitação. Com isso, logo após o resultado, a USP procurou a Itautec para que os produtos fossem de fatos entregues. Segundo Dias (2008), o selo será colocado nos computadores adquiridos pela Itautec para uso da própria faculdade, porém a idéia é ampliar para impressoras e switches. A USP também possui outra iniciativa referente aos equipamentos obsoletos. O projeto é denominado $E$ waste, que tem o objetivo de descartar os equipamentos eletrônicos de informática. Segundo a USP, em 2008 existiam cerca de 40 mil computadores, 15 mil impressoras e 8 mil equipamentos de rede, sendo descartado todo ano $10 \%$ desse material, pois ficam obsoletos.

\section{ANÁLISE DA PESQUISA COM GESTORES E TÉCNICOS DE TECNOLOGIA DA INFORMAÇÃO}

O perfil do universo da pesquisa foi constituído de 8 (oito) organizações públicas $(33 \%)$ e 16 organizações privadas $(67 \%)$. Dessas, $8(33 \%)$ são desenvolvedoras de software. Dentre os respondentes, 7 (29\%) tem formação superior em Sistemas de Informação/ Processamento de Dados/ Ciência da Computação. Os demais, 17 (71\%), tem formação em Administração. Dentre os respondentes, 11 exercem cargo de liderança ou chefia (46\%) na empresa em que trabalha.

No que se refere à existência na empresa de alguma política ambiental voltada à redução do consumo de energia na área de tecnologia, as respostas estão representadas no gráfico abaixo. 


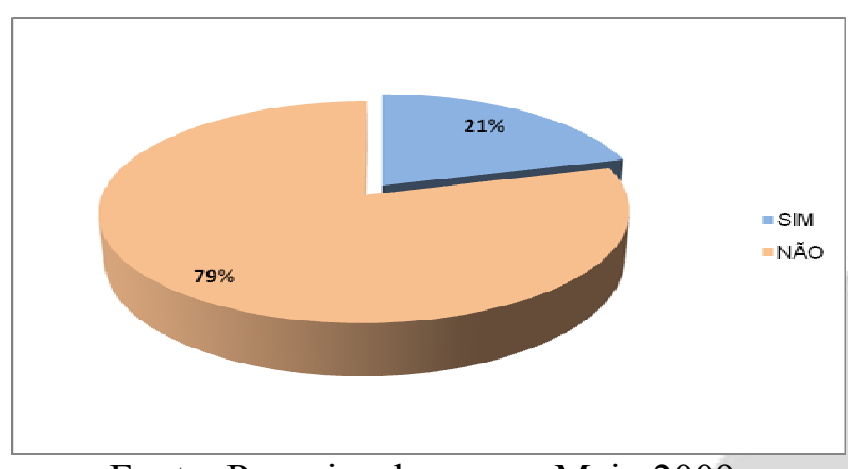

Fonte: Pesquisa de campo Maio 2009.

Gráfico 1: Política ambiental voltada para a redução de energia.

De acordo com o gráfico 1 percebe-se que $79 \%$ das organizações dos entrevistados não possui nenhuma política voltada para a redução de consumo de energia da área de TI, sendo que apenas $21 \%$ possui uma estratégia. Dos $21 \%$, foi respondido que: a organização faz o upgrade dos computadores para a maior eficiência energética; determina o desligamento automático dos monitores quando os mesmo encontram-se ociosos; possui um gerador de energia para a área de TI; e projeto de substituição de monitores convencionais para LCD. Esse percentual contradiz o Computerworld (2009), que mostra, baseado em um estudo da IBM, que $70 \%$ das médias empresas estão praticando projetos voltados para as questões ambientais, referentes ao consumo de energia elétrica, porém esta pesquisa provavelmente foi aplicada em organizações da região Sul/Sudeste e do setor privado, pois é nesta região que existe a maior concentração de organizações que possuem uma grande área de TI, estando aí também os grandes fabricantes e desenvolvedores de TI.

Quanto à questão se a empresa possui alguma estratégia / prática de Gestão Ambiental, os resultados obtidos são apresentados a seguir.

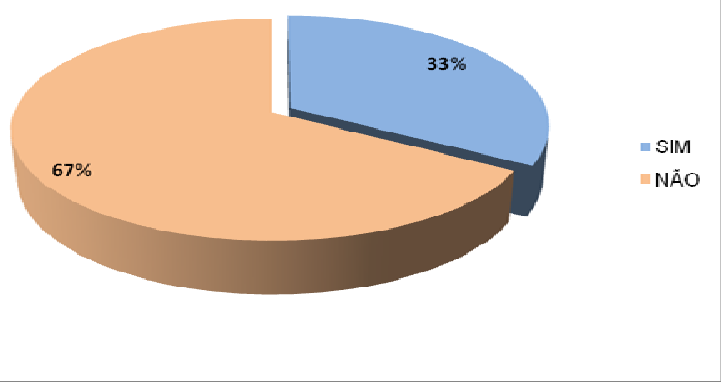

Fonte: Pesquisa de campo Maio 2009.

Gráfico 2: Estratégia / prática ambiental.

Os entrevistados responderam que não possui uma estratégia ambiental por parte das organizações, em grande maioria, conforme o gráfico 2. Que, da mesma forma como citado no gráfico 1, contradiz a pesquisa da IBM. Percebe-se que ainda muitas organizações ainda não incluíram as questões ambientais aos seus planos de desenvolvimento. A menor parte informou que a empresa faz coleta seletiva do lixo produzido, determinou a troca de copos descartáveis por canecas, uso do papel reciclado, troca de sacolas de plásticos por sacolas de pano, recolhimento de baterias (celular, AA e AAA), e reciclagem do lixo produzido.

Em seguida, foi questionado se a empresa dá preferência à compra de equipamentos ecologicamente corretos (com selo verde). 


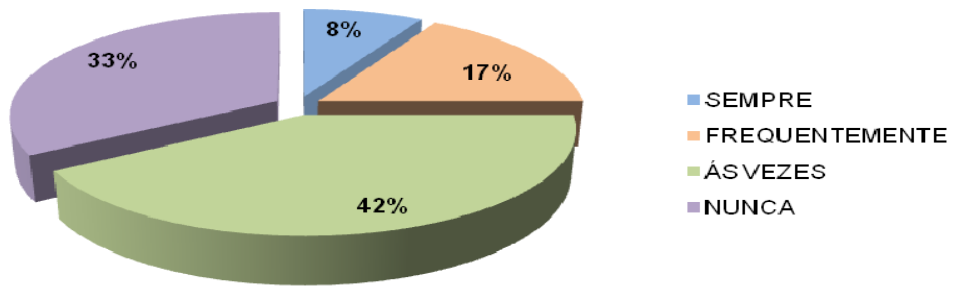

Fonte: Pesquisa de campo Maio 2009.

Gráfico 3: Compra de equipamentos com Selo Verde.

No gráfico 3, os entrevistados respondem na grande maioria que as organizações às vezes compram produtos ecologicamente corretos. Observa-se que é preciso divulgar que os produtos verdes têm, dentre os seus objetivos, a economia da energia elétrica. Entende-se que as organizações em Salvador devem aderir a iniciativas como a da USP, que adquiriu computadores que possuam o selo verde, que não agridem o meio ambiente, se comparados com um computador convencional.

Quanto ao nível de atualização e conservação dos computadores e periféricos utilizados no ambiente de trabalho, as respostas foram:

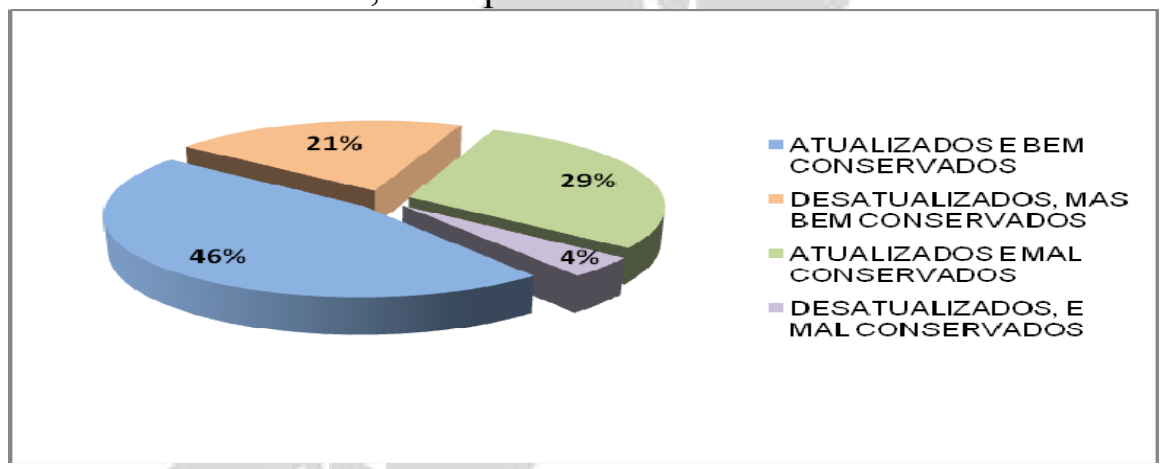

Fonte: Pesquisa de campo Maio 2009.

Gráfico 4: Estado e conservação dos equipamentos.

De acordo com as respostas dos entrevistados, percebe-se que a maioria dos computadores e periféricos utilizados em suas organizações são novos e bem conservados, o que pode se tornar uma variável boa para o meio ambiente, pois as novas tecnologias tentam atender às novas tendências da TI Verde, assim um computador atualizado e bem conservado tende a ser mais econômico do que um desatualizado e mal conservado.

Quanto à questão se a empresa recomenda aos seus funcionários o desligamento automático do monitor quando o mesmo estiver ocioso, o resultado está representado no gráfico 5 . 
Fonte: Pesquisa de campo Maio 2009.

Gráfico 5: Desligamento dos monitores.

De acordo com o gráfico 5, percebe-se que 50\% dos entrevistados configuram o monitor para desligar automaticamente quando o mesmo está ocioso, por recomendação da empresa, porém isto não é obrigatório, e sim opcional dos funcionários. E somente $25 \%$ obrigam seus funcionários a fazer a configuração. Neste caso, as organizações pecam diante desse fator, pois com o desligamento automático dos monitores no final de um período, pode acarretar uma economia de energia elétrica, assim economizando recursos financeiros. Por exemplo, os funcionários de uma determinada organização no horário de almoço, que regularmente varia de uma hora a duas horas, caso o monitor não seja configurado, o desperdício de energia torna-se muito grande.

De acordo com a questão se a organização dá preferência a fazer o upgrade ou comprar novos equipamentos, as respostam foram:

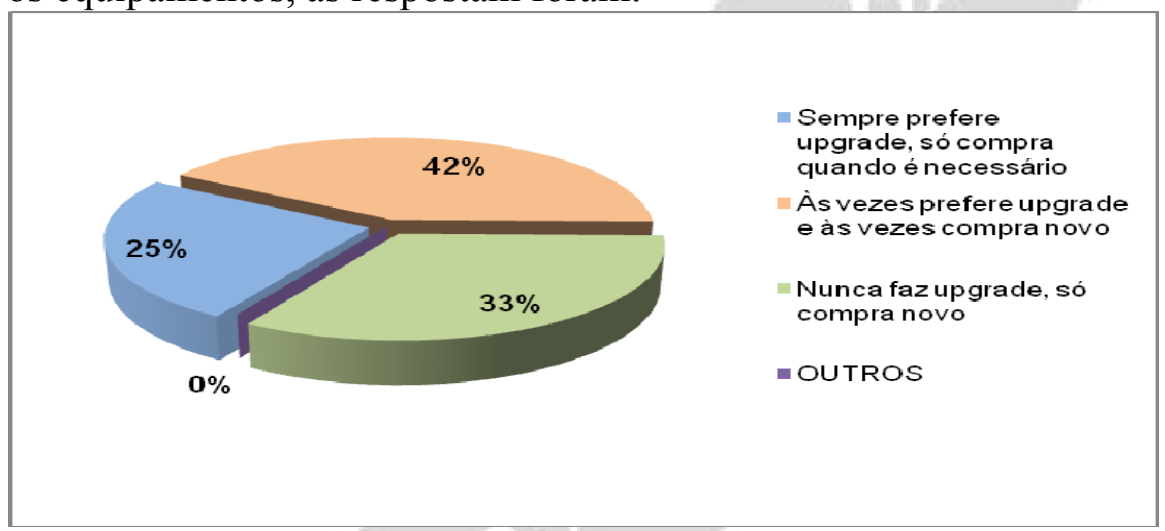

Fonte: Pesquisa de campo Maio 2009.

Gráfico 6: Aquisição e/ou Atualização.

Conforme o gráfico 6, percebe-se que as organizações preferem analisar a questão de comprar uma peça de reposição ou comprar um equipamento novo. Fazer o upgrade muitas vezes sai muito caro, por conta da quantidade de impostos, sendo que a compra de um equipamento novo sai mais em conta, pois a tributação é em cima do equipamento em si e não nas peças. Por isso, em segundo lugar ficam as organizações que nunca faz upgrade, desta forma aumentando a quantidade de lixo eletrônico, pois compram novas máquinas e descartam o equipamento velho ou obsoleto, sendo que só $25 \%$ das organizações preferem fazer o upgrade e só compram quando necessário, desta forma diminuindo a quantidade de lixo tecnológico despejada no meio ambiente, caso a empresa não faça nenhum tipo de doação a ONGs, fornecedores ou a cooperativas de reciclagem.

Quanto à questão se a organização oferece instruções ou treinamento para o descarte dos produtos tecnológicos, as resposta estão representadas no gráfico 7 .

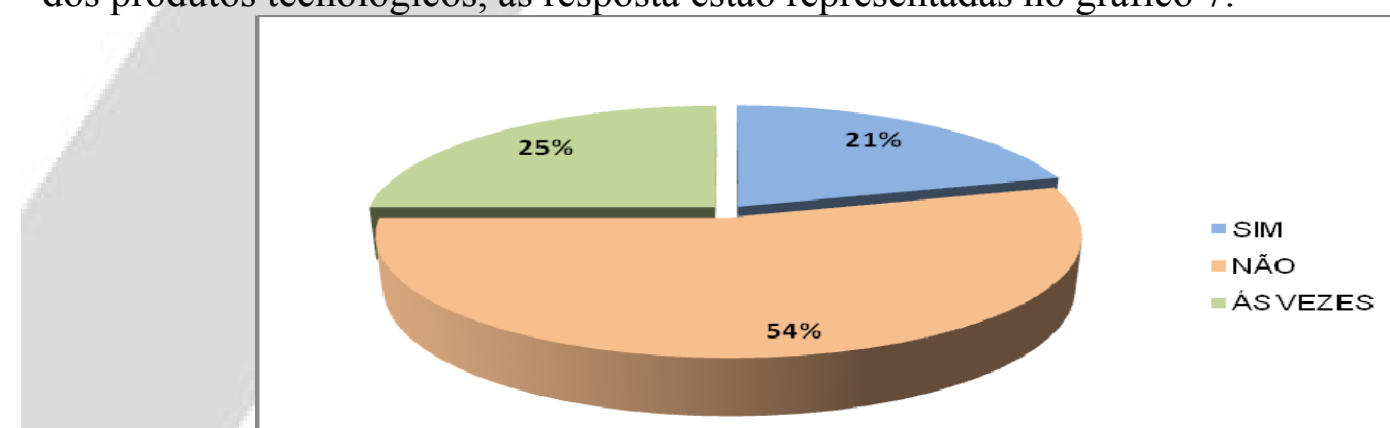


Fonte: Pesquisa de campo Maio 2009.

Gráfico 7: Treinamento para descarte.

Percebe-se no gráfico 7 que a grande maioria das empresas não fazem nenhum treinamento e não oferecem instruções para o descarte dos produtos tecnológicos, sendo que nos dias atuais, onde as questões ambientais estão cada vez mais presentes nas organizações e no cotidiano da sociedade, ainda muitas organizações em Salvador não praticam nenhum tipo de treinamento voltado para as questões ambientais nem relacionados ao lixo tecnológico.

Quanto à questão sobre o que a empresa faz com os equipamentos obsoletos ou quebrados, as respostam foram:

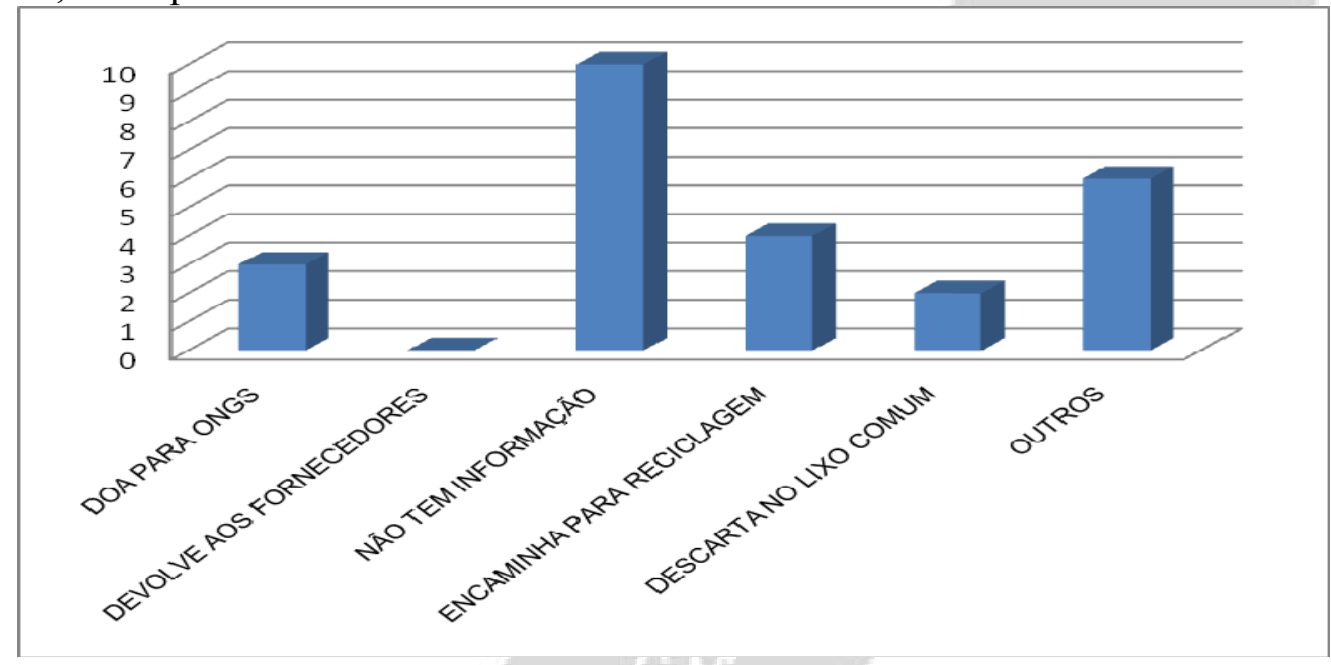

Fonte: Pesquisa de campo Maio 2009.

Gráfico 8: Destino dos equipamento das organizações.

O gráfico 8 mostra o destino que as empresas dão aos equipamentos obsoletos. Porém, a grande maioria dos entrevistados não tem essa informação, contudo, para que uma estratégia ambiental tenha um ótimo resultado tanto para a organização como para o meio ambiente são necessárias a participação e compreensão de todos que estão dentro da organização. A segunda resposta mais escolhida foi a opção Outros e dentre as respostas se destacam duas pelo lado negativo; a primeira o entrevistado informou que a organização manda para um incinerador, o que afeta a camada de ozônio, pois, com a incineração, gases altamente tóxicos são liberados, a outra organização doa as máquinas para catadores de lixo, porém acredita-se que um catador de lixo não sabe dar um tratamento de reciclagem a um equipamento como o computador que possui mais de 1.000 componentes diferentes, dentre eles chumbo, cádmio, que são altamente tóxicos a saúde humana. Agumas empresas doam para ONGs e encaminham para cooperativas de reciclagem, ainda sim existem empresas que descartam em lixo comum, o que pode acarretar a contaminação de lençóis freáticos, solo, entre outros.

De acordo com a questão se o entrevistado dá preferência à compra de equipamentos ecologicamente com selo verde, mesmo mais caro, as respostas estão no gráfico abaixo: 


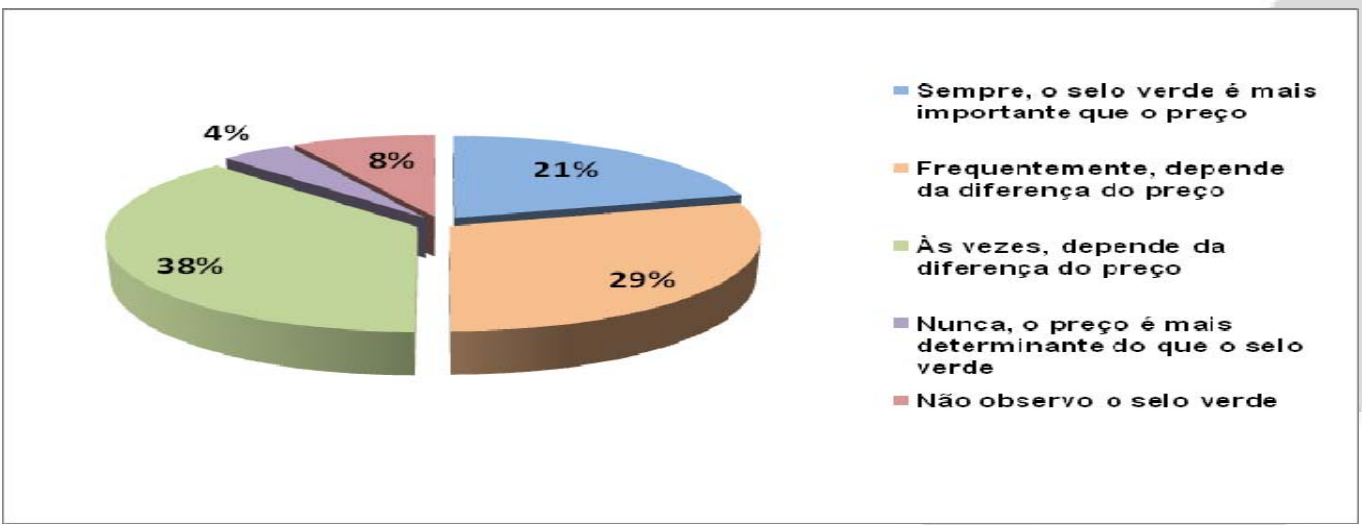

Fonte: Pesquisa de campo Maio 2009.

Gráfico 9: Compra de equipamentos Verdes para os usuários.

No gráfico 9 percebe-se que a grande maioria dos entrevistados tendem a comprar equipamentos que sejam considerados verdes, porém, o que determina, segundo as respostas dos entrevistados, é o preço, pois os produtos verdes ainda são mais caros que o equipamentos comuns, o que mostra uma real necessidade em investimentos na área de pesquisa $\mathrm{e}$ desenvolvimento (P\&D), para que possa baratear essa nova tecnologia, tornando-se assim mais accessível aos consumidores. Contudo, pode-se analisar que o consumidor tem a pretensão de comprar equipamentos que não agridam o meio ambiente, mostrando assim, uma possível preocupação com as questões ambientais.

Foi questionado também se o entrevistado prefere fazer upgrade no seu PC ou comprar um novo, o resultado obtido está representado no gráfico 10.

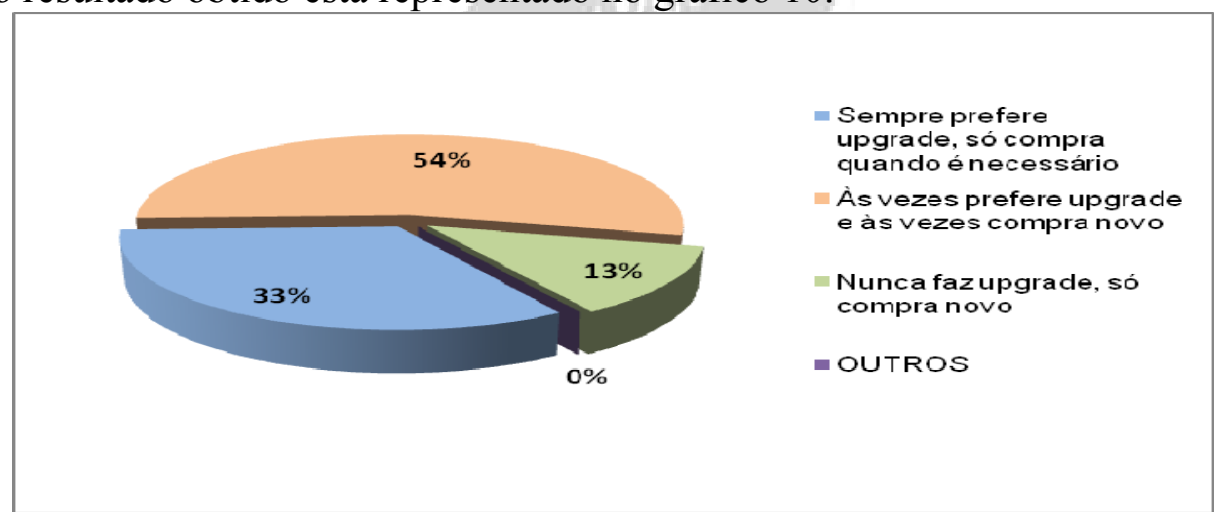

Fonte: Pesquisa de campo Maio 2009.

Gráfico 10: Aquisição e/ou Atualização para os usuários.

De acordo com o gráfico 10, os entrevistados às vezes preferem fazer o upgrade ou comprar novos equipamentos, o que vai determinar essa escolha será o valor gasto pela compra da peça ou do equipamento completo. Conforme visto também no gráfico 6, fazer o upgrade para o meio ambiente é a melhor opção, pois caso uma placa-mãe fique com defeito, o usuário irá comprar um novo computador? Caso a resposta seja positiva, qual será o destino do computador obsoleto? Muitas vezes o equipamento obsoleto ficará armazenado em casa. Conforme visto em Executive Briefing, o armazenamento de equipamentos obsoletos torna-se ruim para o meio ambiente, pois o usuário fica guardando os equipamentos para fazer reciclagem, porém com o tempo não faz a entrega desse material e acaba dando o destino do lixo comum. Contudo, de uma forma geral, o gráfico 10 mostra uma visão positiva referente à posição do usuário para com o meio ambiente, pois se os equipamentos verdes não tivessem os preços tão discrepantes o gráfico poderia ser outro. 
Quanto ao destino que o entrevistado dá os produtos eletrônicos obsoletos ou quebrados, os resultados obtidos são apresentados a seguir.

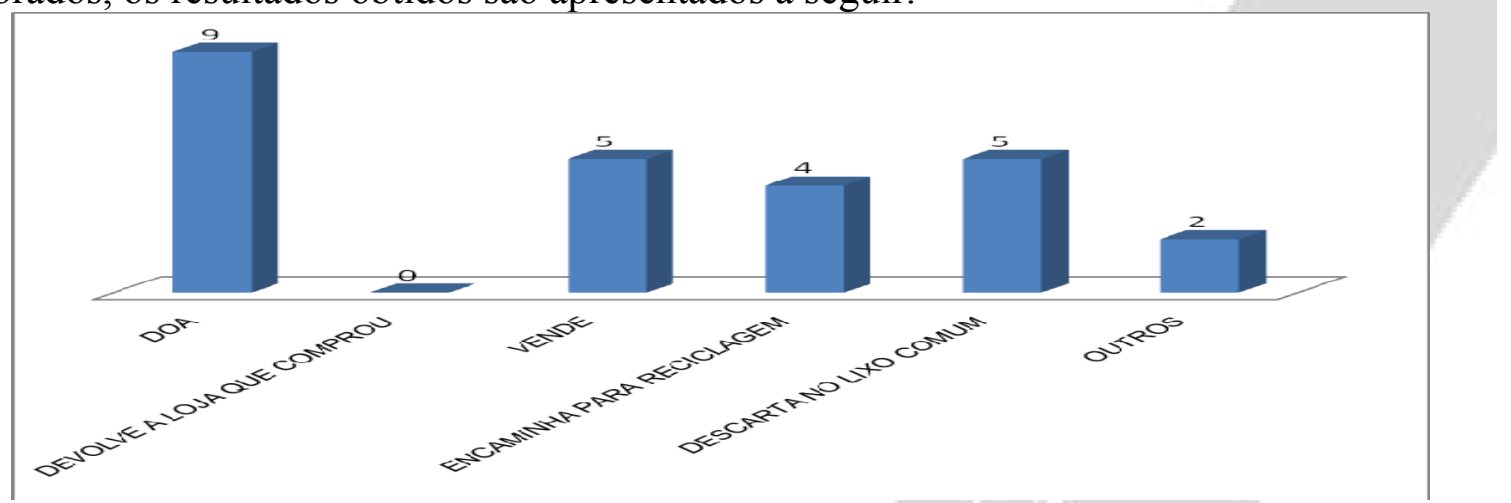

Fonte: Pesquisa de campo Maio 2009.

Gráfico 11: Destino dos equipamentos para usuários.

Conforme o Gráfico 11, os entrevistados, em grande parte, dão um bom destino aos equipamentos quebrados ou obsoletos, contudo percebe-se que não existe nenhum tipo de logística reversa sendo praticada pelos fabricantes, ou, se existe, não é bastante difundida na mídia para que os usuários possam entregar os equipamentos, pois houve entrevistado que informou que armazena em casa, porque não sabe o que fazer. Há usuários que vendem seus equipamentos, praticando assim o re-upgrade, desse modo, passando para outros usuários que podem reparar o equipamento e reutilizá-lo. Porém, ainda há usuários que descartam seus equipamentos eletrônicos no lixo comum, contribuindo para o aumento do impacto ambiental.

No que se refere às iniciativas adotadas para diminuir o consumo de energia dos equipamentos de TI, em casa ou no trabalho, os entrevistados se dividiram em três grupos. O primeiro grupo é constituído dos entrevistados que não tomam nenhuma atitude para economizar energia. O segundo é constituído pelos entrevistados que tomam atitudes simples para a redução de consumo elétrico, como por exemplo, o desligamento automático dos monitores quando os mesmos encontram-se em tempo ocioso, não deixam os equipamentos em stand-by (baixo consumo), tirando todos os equipamentos da tomada. E, por fim, o terceiro grupo, que é constituído pelos entrevistados que tem uma consciência maior dos problemas ambientais, e com isso, além de configurar o monitor para o desligamento automático, configuram o sistema operacional do computador para operar com o baixo consumo de energia elétrica, desta forma comprometendo o desempenho gráfico do computador. Houve ainda outro que informou que faz o upgrade trocando o monitor de convencionais para LCD, os HDs e Gravadores de DVD de IDE para SATA.

Foi perguntado aos gestores e técnicos de TI sobre o que compreendiam acerca do conceito de TI Verde. Da mesma forma que a questão anterior, os entrevistados estão divididos em três grupos. O primeiro grupo, constituído por apenas um entrevistado, não possui nenhum tipo de conhecimento do conceito de Tecnologia da Informação Verde, e que, por causa do questionário, ele percebeu que tinha algo relacionado com a redução de consumo enérgico e melhor tipo de descarte para o lixo tecnológico. O segundo grupo é composto pelos entrevistados que possuem um razoável conhecimento do conceito da TI Verde, ou pelo menos tem a consciência do foco da mesma, como: Tecnologia da Informação voltada à política de preservação ambiental; Tecnologia da Informação Ecologicamente Correta; TI Verde é a tecnologia preocupada com o meio ambiente. Percebe-se que neste grupo os entrevistados têm consciência que a TI Verde tem uma relação de preocupação com o meio ambiente, sendo assim podendo atuar na organização sem causar impactos ambientais. Soares (2005) define a TI Verde como a tecnologia que defende o uso de tecnologias limpas e 
acarretem o menor uso de energia elétrica, que também possam ser recicladas e reutilizadas. O terceiro grupo demonstra um nível de conhecimento do conceito muito avançado quando comparados aos outros entrevistados, como por exemplo:

- A produção mais limpa de equipamentos tecnológicos, ou seja, utilizando menos água no processo industrial e menos materiais pesados, como chumbo; o investimento em pesquisa, por parte das empresas e da academia, em produtos tecnológicos que contenham mais materiais recicláveis e que consumam menos energia; a adesão a normas internacionais de selo verde; a responsabilidade ambiental das empresas em promover a logística reversa; as políticas públicas de governo para incentivar e fiscalizar sistemas de gestão ambiental que incluam a TI; a conscientização de gestores e técnicos de TI para divulgar e adotar a TI Verde; a educação ambiental dos usuários para fazer o descarte correto do lixo tecnológico (LT); a implantação de coleta municipal específica para o LT; a organização e profissionalização de cooperativas de reciclagem especializadas em lixo tecnológico; a divulgação do conceito de metareciclagem; a implantação de programas de gestão ambiental na área de TI. Enfim, a área de TI, nas empresas e no uso doméstico, deve estar também engajada com a melhoria do ambiente planetário, sendo urgente a mudança para uma TI Sustentável, haja vista que os grandes desastres ecológicos, que antes eram apenas ameaças, já tornaram-se realidade, inclusive em Salvador;

- O conceito empresa verde reflete a maneira como uma empresa trata e mantém suas operações sempre embasadas em políticas que visam a redução do impacto ambiental causado por sua atividade. Essa iniciativa (obrigação) deve ser trabalhada internamente a nível departamental e não apenas em seus produtos. Iniciativas como essa apenas são realmente adotadas e duradouras se conseguirem penetrar no DNA da empresa e não apenas no discurso ou poucas ações, mas para isso o apoio da alta direção é decisivo. É importante citar que ser uma empresa verde não é simples e nem rápido, mas sim um processo gradativo e contínuo. Não significa apenas cortar uma árvore e plantar outra, ou mesmo neutralizar o uso de carbono. Ser verde vai muito além e deve envolver a conscientização dos colaboradores em todos os departamentos da empresa;

- Utilização de maior eficiência energética, diminuição de componentes químicos que deixam resíduos no ambiente, reciclagem de equipamentos; e

- Eficiência na utilização dos recursos computacionais, promovendo reciclagem ou biodegradabilidade dos itens que estão fora de uso.

Com isso, percebe-se que este grupo de entrevistados possui um nível mais avançado de conhecimento sobre o conceito de TI Verde.

Conclui-se que ainda são poucas as iniciativas existentes para a adoção de Tecnologia da Informação Verde nas organizações baianas. Contudo, ainda a maior dificuldade para a inserção da TI Verde é justamente o custo elevado para a aquisição dessas novas tecnologias, o que torna imprescindível um maior investimento em pesquisa e desenvolvimento na área de TI para tornar viável a inserção da TI Verde nas organizações.

\section{CONSIDERAÇÕES FINAIS}

Diante do que foi exposto neste trabalho, o conceito de Tecnologia da Informação Verde (TI Verde) torna-se muito importante tanto para a conservação e prevenção do meio ambiente, como para as organizações, pois os principais objetivos da TI Verde é a 
redução do consumo de energia e insumos não renováveis, desenvolvimentos de produtos sem substâncias tóxicas, redução de desperdício de matérias-primas no processo de produção, apoio no desenvolvimento de produtos que possam ser reutilizados e de fácil reciclagem. Apesar de ser uma das vias para minimizar os problemas dos impactos ambientais referentes às ações das organizações, muitas destas em Salvador ainda não possuem nenhum tipo de projeto ambiental, mesmo sendo organizações que desenvolvem software, das 24 (vinte e quatro) organizações entrevistadas, 8 (oito) são produtoras de softwares e apenas 3 (três) delas possuem alguma estratégia ou projeto ambiental.

O maior desafio encontrado para as organizações adotarem a TI Verde é o custo para fazer a troca do parque tecnológico da organização, pois, para adquirir um produto considerado verde é necessário desembolsar um valor maior do que um produto convencional. Entretanto, as organizações, que são pressionadas a darem resultados cada vez mais rápidos aos acionistas, estarão dispostas a fazer os investimentos necessários para a adoção da TI Verde? De acordo com os resultados da pesquisa, a maioria, quase $70 \%$ das organizações da cidade de Salvador, não está disposta. O que contradiz com as necessidades do mundo atual, onde a demanda por resultados ambientais são cada vez mais cobrados pelos consumidores conscientes e pela sociedade civil como um todo.

Assim, o pressuposto que norteou essa pesquisa foi que as metas organizacionais de atualização tecnológica, uso intensivo da tecnologia para a competitividade e evolução dos parques tecnológicos entram em conflito com a adoção de medidas e práticas da TI Verde. O pressuposto se confirma, pois as evoluções tecnológicas oferecem maior capacidade de processamento de dados por um custo mais baixo, porém a resistência para a adoção da TI Verde é formada pelo valor do investimento de adoção da TI. No entanto, é necessário compreender que hoje a TI é considerada agente passivo para o aquecimento global, pois, embora a TI tenha proporcionado às organizações um alto nível de produtividade, por outro lado, aumentou a quantidade do consumo de materiais-primas não renováveis, a quantidade de lixo tecnológico no meio ambiente, e que a TI Verde a médio e longo prazo pode trazer inúmeros benefícios para a organização, com a redução dos custos com insumos como energia elétrica, água, insumos não renováveis.

Percebe-se que o nível de informação do conceito de TI Verde é considerado bom, pois a maioria dos entrevistados entende a TI Verde como o uso da tecnologia aliado à preservação do meio ambiente, e apenas um entrevistado informou que nunca tinha ouvido falar em TI Verde. Com isso, pode-se analisar que, apesar da maioria das organizações da cidade de Salvador não praticarem algum tipo de investimento na área ambiental, a maioria dos profissionais da área tem o conhecimento da TI Verde. Na perspectiva de todo o território brasileiro, percebe-se, no decorrer dos estudos, um desnível muito grande entre a região nordeste e a região sul/sudeste, onde ficam mais concentradas as multinacionais da área de TI. A forma como as organizações se comportam diante da adoção de tecnologias mais limpas mudam, no sul/sudeste as organizações entrelaçam suas metas de desenvolvimento com as metas ambientais, até por uma questão política, visto que a pressão das normas internacionais e das organizações ambientalistas, como o Greenpeace, que denuncia na Internet as empresas de TI que não aderem às boas práticas ambientais, constituem fatores determinantes na fiscalização, principalmente quando se trata de lixo tecnológico.

Outro fator a ser considerado é a grande quantidade de empresas de reciclagem de equipamentos eletrônicos na região sul e sudeste, diferente do que se vê na cidade de Salvador. Quando não existe uma maior fiscalização que impeça as organizações de jogarem seus resíduos da produção e o lixo tecnológico no lixo comum, fica inviável abrir uma empresa de reciclagem nesta cidade. Outro fator interessante da TI Verde obtido nesta 
pesquisa é que a mesma não está só ligada às organizações que fabricam, por exemplo, computadores, celulares, televisores $\mathrm{mp} 3$, ou seja, organizações que produzem equipamentos para a utilização do homem. Porém, a TI Verde está produzindo equipamentos voltados para a utilização em melhorias do meio ambiente, como, por exemplo, a solução da emissão do dióxido de carbono na atmosfera, com a máquina que limpa o ar, aquecendo o mesmo a uma temperatura de $400^{\circ} \mathrm{C}$ junto com hidróxido de sódio, dessa forma limpando o ar e utilizando energia solar para realizar o processo.

A pesquisa possui limitações, pela parca literatura sobre TI Verde, pela abrangência a 24 (vinte e quatro) organizações, e por não existir em Salvador uma empresa que servisse de estudo para melhor aprofundamento nos processos de produção. Contudo, recomenda-se que o Estado e as empresas invistam em grande escala em Pesquisa e Desenvolvimento na área de TI, para que essas tecnologias possam ficar mais baratas e accessíveis as organizações, assim podendo adotar as tecnologias mais limpas no seu processo de produção. Como, da mesma forma, recomenda-se que o Governo faça um papel mais efetivo em relação à fiscalização dos produtos que possuam materiais tóxicos em sua composição, em determinar as organizações a fazerem a logística reversa de seus produtos eletroeletrônicos, fomentar a área da reciclagem e reutilização, para que os custos também diminuam, tornando-se assim viável ao consumidor final, e, por final, fazer eventos que mostrem à população a importância de darem o melhor destino aos materiais eletrônicos.

Diante do que foi exposto no trabalho, a Tecnologia da Informação Verde torna-se indispensável para todas as organizações, independente do seu ramo e tamanho, pois os problemas ambientais globais chegaram a tal nível que todos os esforços individuais e coletivos devem ser empreendidos na direção de soluções.

\section{REFERÊNCIAS}

Computerworld. (2009) TI verde está nos planos de 70\% das médias empresas brasileiras, diz estudo. Recuperado em 15 de maio, 2009, de http://pcworld.uol.com.br/noticias/2009/05/13/ti-verde-esta-nos-planos-de-70-das-mediasempresas-brasileiras-diz-estudo/

Computerworld. (n.d.) Executive Briefing. Guia do executivo para decisões estratégicas. O que é preciso saber para adotar a TI Verde. Recuperado em 14 de março, 2009, de http://www.rs.sucesu.org.br/arquivos/TIVerde.pdf

Dias, V. (2008) USP utilizará micros ambientalmente sustentáveis e com "selo verde". Recuperado em $1^{\circ}$ de maio, 2009, de http://www2.usp.br/index.php/tecnologia/15585-usputilizara-micros-ambientalmente-sustentaveis-e-com-qselo-verdeq

Greenpeace. (2009) Seu guia de eletrônicos verdes. Recuperado em 20 de maio, 2009, de http://www.greenpeace.org/international/news/green-electronics-guide-ewaste250806

Info. Redação. (2009). Economizar energia vale o quanto pesa em TI. Recuperado em $1^{\circ}$ de abril, 2009, de http://info.abril.com.br/ti-verde/economizar-energia-vale-o-quan.shtml

Macohin, A. (2008) A sustentabilidade na Informática - Reciclagem e Eliminação dos produtos tóxicos das peças de computadores. Recuperado em 20 de abril, 2009, de http://www.fae.edu/nucleos/pdf/primeiro_seminario/sustentabilidade_informatica_aline.pdf 
Moreno, J. B. (2009) Monitor “assiste” usuário para economizar energia. Giga Blog Recuperado em 28 de abril, 2009, de http://uoltecnologia.blog.uol.com.br/mundoweb/.

Pendler, L. (2009) Da euforia da TI verde surgem soluções que cortam custos e economizam energia. Recuperado em 18 de abril, 2009, de http://www.mmbrasil.com.br/index.php?option=com_content\&task=view\&id=283\&Itemid=7 0

Roesch, S. M. A. (2007) Projetos de estágios e de pesquisa em administração: Guia para Estágios, Trabalhos de conclusão, dissertação e Estudos de caso. $3^{\mathrm{a}}$ ed. São Paulo: Atlas.

Soares, E. (2005) Reduza custos com a TI Verde. ITPro: Corporativo. Recuperado em 10 de maio, 2009 , de http://wnews.uol.com.br/site/noticias/materia_especial.php?id_secao=17\&id_conteudo=579

SPCTi Reciclagem (2009). 315 milhões de máquinas no lixo. Recuperado em 11 de abril, 2009, de http://www.spcti.com.br/lix_ele003.htm

Zmogimski, F. (2009a) Experimento usa luz do Sol para limpar ar. Recuperado em 27 de abril, 2009, de http://info.abril.com.br/ti-verde/experimento-usa-luz-do-sol-par.shtml

Zmogimski, F. (2009b) Sua casa vai virar uma usina elétrica. Recuperado em $1^{\circ}$ abril , 2009, de http://info.abril.com.br/ti-verde/sua-casa-vai-virar-uma-usina-e.shtml 